\title{
El papel de los medios de comunicación para la igualdad de género
}

\author{
El papel de los medios de comunicación para la igualdad de género. Recibido: 14/08/2014 - Aceptado: 22/09/2014
}

\begin{abstract}
De reinas a ciudadanas: Medios de comunicación, ¿motor o rémora para la igualdad?
\end{abstract}

Juana GALLEGO

España: Aresta Mujeres, 2013.

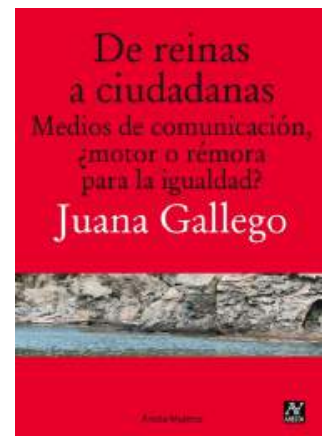

309 páginas

ISBN: 978-84-941456-1-2

\section{Carla CERQUEIRA}

Investigadora de Pós-Doctorado. Universidad do Minho. Portugal. carlaprec3@gmail.com

El libro "De reinas a ciudadanas: Medios de comunicación, ¿motor o rémora para la igualdad?" se dirige a un público que se interesa por las temáticas de los medios de comunicación, igualdad de género y ciudadanía. A lo largo de sus 10 capítulos, este libro traza el panorama general en las más diversas áreas comunicativas, pasando por el periodismo, la prensa femenina, la televisión, la radio, la publicidad y hasta el cine.

La autora, la investigadora española Juana Gallego, empieza por destacar en el inicio del libro que el siglo XX fue fundamental en lo que se refiere al cambio social vivenciado por las mujeres en el área de la comunicación y las tecnologías. "Naturalmente que ha habido otros muchos cambios que han transformado nuestro mundo y nuestra vida, pero a mi juicio ninguno tan apabullante y espectacular (...)" (Gallego, 2013:13). Igualmente, queda claro para la autora que la incorporación de las mujeres a la profesión periodística no se encuentra vinculada con la producción de contenidos porque hay una cultura profesional que está imbuida de una cosmovisión de género androcéntrica (Gallego, 2013:25). Por eso, Juana Gallego presenta investigaciones que muestran que hay una dicotomía entre ellos que hacen (las acciones) y ellas que son (reinas, sirenas, damas, damas de hierro, viudas negras, muñecas, niñas, novias...).

Uno de los ámbitos en los que más profundiza es en el de la prensa femenina, y cómo esta crea un modelo de mujer ideal con un determinado estilo de vida. "El fenómeno de la prensa femenina (...) no es ni nuevo ni coyuntural ni, naturalmente, exclusivo de nuestro país (Gallego, 2013:114). Para la autora esos medios de comunicación no proponen modelos autónomos y liberadores sino que siguen defendiendo los intereses masculinos (Gallego, 2013:114).

En el capítulo dedicado a la televisión, la investigadora traza el panorama en el escenario informativo y de entretenimiento. Termina afirmando que los estudios demuestran que la representación de hombres y mujeres continúa siendo muy 
desigual y asimétrica (Gallego, 2013:208). $\mathrm{La}$ radio, uno de los medios menos estudiados, tenía un fuerte público femenino, sin embargo, los estudios vienen demostrando que la representación que hace del mundo es muy parecida a la de la televisión (Gallego , 2013:214).

Por lo que respecta al área publicitaria, la investigadora traza sucintamente el panorama histórico y termina cuestionándose sobre cómo incorporar valores que no sean sexistas, alertando, igualmente, a las personas de la necesidad de una mirada crítica hacia los contenidos publicitarios. "La única posibilidad de combatir este discurso eufórico, de tal manera que no nos influya más allá de lo razonable, es adoptar una actitud distanciada" (Gallego, 2013: 238).

En lo que concierne al cine como producto cultural, teniendo como base investigaciones en el área, sostiene que éste continua canalizando la violencia contra las mujeres, particularmente contra las prostitutas, sin posicionarse críticamente. Además, sigue privilegiando la figura masculina en el centro de la acción narrativa (Gallego, 2013:247).

Una de las ideas transversales en el libro refiere a los medios como constructores y perpetuadores o transformadores de la realidad, de ahí la importancia de lo que dicen y de la forma en que lo hacen (Gallego, 2013:249). La autora subraya en este libro que la lectura de la realidad hecha por los más diversos medios de comunicación es compleja, si bien en la medida en que incorporen los valores de profundidad, rigor y pluralidad serán más inclusivos.

El análisis hecho por Juana Gallego evidencia que en ciertos momentos los medios funcionaron como potentes motores para la igualdad y la transformación social, pero en este momento puede afirmarse que son más una rémora. Concluye con la idea de que las mujeres no pueden continuar siendo vistas como el "otro", sino como parte integrante del "nosotros" que constituye una sociedad diversa. Por lo tanto, no son reinas, sino ciudadanas (Gallego, 2013:251). Además, en el libro se proponen líneas para informar con perspectiva de género o cómo eliminar los estereotipos y presentar contenidos más diversos e inclusivos.

En esta obra son también destacables los anexos, ya que abarcan algunas áreas de investigación en el campo de los estudios de género y medios: historia de la prensa femenina y de la prensa del corazón; grupos de prensa internacionales; revistas masculinas.

Juana Gallego tiene una trayectoria de investigación académica y activismo ligada a los estudios de género y comunicación, siendo esta su obra más reciente, en la cual compila gran parte del trabajo de investigación que ha hecho.

\section{Forma de citación}

CERQUEIRA, Carla: El papel de los medios de comunicación para la igualdad de género. Revista Communication Papers, $N^{\circ} 5$, páginas 103 a104. Departamento de Filología y Comunicación de la Universidad de Girona. Recuperado el __ de de 2 de: http://www.communicationpapers.es 